\title{
Increased Trypanosoma spp. richness and prevalence of haemoparasite co-infection following translocation
}

\author{
Amy S. Northover ${ }^{1 *}$ (D), Stephanie S. Godfrey ${ }^{2}$, Sarah Keatley ${ }^{1}$, Alan J. Lymbery ${ }^{3}$, Adrian F. Wayne ${ }^{4}$, \\ Crystal Cooper ${ }^{1}$, Louise Pallant ${ }^{1}$, Keith Morris ${ }^{5}$ and R. C. Andrew Thompson ${ }^{1}$
}

\begin{abstract}
Background: Understanding how fauna translocation and antiparasitic drug treatment impact parasite community structure within a host is vital for optimising translocation outcomes. Trypanosoma spp. and piroplasms (Babesia and Theileria spp.) are known to infect Australian marsupials, including the woylie (Bettongia penicillata). However relatively little is known about these haemoparasites, or how they respond to management practices such as translocation. We monitored haemoparasites infecting woylies for up to 12 months during two fauna translocations to supplement existing woylie populations in three different sites (Dryandra, Walcott and Warrup East) within south-western Australia between 2014 and 2016, with the aim of investigating (i) how haemoparasite prevalence, Trypanosoma spp. richness and Trypanosoma spp. community composition varied over time and between different sites following translocation; and (ii) whether ivermectin treatment indirectly impacts haemoparasite prevalence. Using molecular methods, 1211 blood samples were screened for the presence of trypanosomes, and a subset of these samples $(n=264)$ were also tested for piroplasms.
\end{abstract}

Results: Trypanosomes and piroplasms were identified in 55\% and $94 \%$ of blood samples, respectively. We identified five Trypanosoma species, two Theileria species, a single species of Babesia and a novel Bodo species. Trypanosoma spp. richness and the prevalence of haemoparasite co-infection increased after translocation. Prior to translocation, Trypanosoma spp. community composition differed significantly between translocated and resident woylies within Walcott and Warrup East, but not Dryandra. Six months later, there was a significant difference between translocated and resident woylies within Dryandra, but not Walcott or Warrup East. The response of haemoparasites to translocation was highly site-specific, with predominant changes to the haemoparasite community in translocated woylies occurring within the first few months following translocation. Ivermectin treatment had no significant effect on haemoparasite prevalence.

Conclusions: This study contributes to our understanding of haemoparasite dynamics in woylies following translocation. The highly site-specific and rapid response of haemoparasites to translocation highlights the need to better understand what drives these effects. Given that haemoparasite prevalence and composition of translocated and resident animals changed significantly following translocation, we propose that parasite monitoring should form an essential component of translocation protocols, and such protocols should endeavour to monitor translocated hosts and cohabiting species.

Keywords: Babesia, Bettongia penicillata, Fauna translocation, Piroplasm, Polyparasitism, Theileria, Trypanosome

\footnotetext{
*Correspondence: a.northover@murdoch.edu.au

${ }^{1}$ College of Science, Health, Engineering and Education, Murdoch

University, 90 South Street, Murdoch, Western Australia 6150, Australia

Full list of author information is available at the end of the article
} 


\section{Background}

Suitably termed a "biological package", a host and its suite of parasites are unique, coexisting but continually adapting entities, enhancing the competitive fitness and ultimately affecting the survival of one another $[1,2]$. While it is now recognised that polyparasitism (co-infection, concomitant infection or multiparasitism) is the rule rather than the exception in wildlife [3, 4], deciphering the manner in which parasites interact with each other and their host is complex; even more so in situations where perturbations to the host-parasite community are likely to occur.

Fauna translocations play a pivotal role in the management of threatened species worldwide. However, the act of moving a host and its infracommunity of parasites from one ecosystem to another will inevitably disrupt host-parasite associations $[2,5,6]$. Changes in the composition of the parasite community may significantly impact host health and population dynamics [7]. Likewise, translocation-associated stress may enhance susceptibility to parasite infection [8], or promote recrudescence of latent disease [9]. Unfortunately, translocation protocols rarely incorporate parasite monitoring and field studies that examine parasite prevalence pre- and post-translocation, e.g. [10] are rare; thus we lack an understanding of how translocation impacts the host-parasite community [11]. Additionally, antiparasitic drugs may be administered to a host, often without any attempt to evaluate treatment efficacy [12]. With demonstrated effects of antiparasitic drugs in target and non-target parasites, e.g. [13], there is the potential to negatively impact translocation outcomes.

The critically endangered woylie (syn. brush-tailed bettong Bettongia penicillata) is a small macropodid marsupial, which once occupied most of southern Australia. Adult woylies weigh between $1.0-1.6 \mathrm{~kg}$, measure roughly $600 \mathrm{~mm}$ in length (nose to tail tip) and live for approximately 4-6 years in the wild [14]. Over the past decade, woylies have undergone greater than $90 \%$ population declines and are now restricted to three remaining wild indigenous populations (Kingston, Perup and Dryandra) in south-western Australia [15]. Both the Kingston and Perup woylie populations are located within the Upper Warren region, where woylie population declines were most pronounced [16]. While various hypotheses have been proposed to explain the declines, their spatio-temporal pattern suggests the potential role of an infectious disease agent [15]. Woylie monitoring carried out immediately prior to, and during the declines, detected a high prevalence of skin disease, but despite investigation, a causative disease agent could not be found [16]. Since then, the focus of investigation has shifted toward the potential role of other disease agents and Trypanosoma spp. have been of particular interest [17-20].

Five Trypanosoma species have been detected in woylies: T. copemani, T. vegrandis [18], T. noyesi [21], Trypanosoma sp. ANU2 and T. gilletti [22]. Two distinct genotypes of T. copemani are formally recognised, $T$. copemani genotype 1 (G1) and T. copemani genotype 2 (G2) [18]. Trypanosoma copemani G2 has been detected in woylie tissues by PCR, associated with tissue pathology, and is capable of invading cells in vitro $[18,23]$. Molecular studies have identified a higher prevalence of T. copemani and Trypanosoma spp. coinfection in a declining woylie population compared to a stable population [17-19], and the extent of Trypanosoma co-infection was found to increase during the decline [20].

Various piroplasms (Theileria and Babesia spp.) have also been identified in Australian wildlife, including Theileria penicillata [24] and a Babesia sp. [25] in woylies. While piroplasms have been associated with significant clinical disease in domestic livestock and companion animals [26], relatively little is known about their biology, transmission and clinical impact within native Australian wildlife [27]. To date, Th. penicillata has been detected at high prevalence $(>80 \%)$ in several woylie populations [28], while Babesia sp. infection has been found at moderate prevalence $(47 \%)$ in a single wild woylie population [25].

As part of ongoing management of the woylie, remaining wild populations are periodically supplemented by translocations [15]. Like many threatened wildlife species, parasite monitoring is not routinely undertaken and there is little understanding of how translocations impact parasite community structure in woylies. In this longitudinal field-based study, we examined Trypanosoma spp. and piroplasms (Theileria and Babesia spp.) infecting woylies during two translocations to supplement existing woylie populations. Specifically, we aimed to investigate (i) how haemoparasite prevalence, Trypanosoma spp. richness and Trypanosoma spp. community composition varied over time and between different sites following translocation; and (ii) whether ivermectin treatment indirectly affects haemoparasite prevalence. We predicted that haemoparasite prevalence would decrease following translocation, in a similar manner to fauna reintroductions, where parasite loss commonly occurs [29, 30]. As ivermectin targets nematodes and arthropods, we did not expect ivermectin to directly affect Trypanosoma spp. prevalence in woylies, but we predicted that the impact of ivermectin on arthropod vectors may indirectly reduce trypanosome transmission. 


\section{Methods}

\section{Study sites and trapping regime}

During the first translocation (June 2014), 182 woylies were translocated from Perup Sanctuary, a 423-ha fenced reserve situated within the Tone-Perup Nature Reserve near Manjimup in Western Australia (34.2506 ${ }^{\circ}$ S, $\left.116.1425^{\circ} \mathrm{E}\right)$, to supplement two unfenced wild populations [Walcott $(n=92)$ and Warrup East $(n=90)$ ] within the Upper Warren region (Fig. 1). Much of the native forests within this region are dominated by jarrah (Eucalyptus marginata), marri (Corymbia callophyla), and occasionally wandoo (Eucalyptus wandoo) [15]. During the translocation, woylies (equal ratio of male to female) were captured over three consecutive nights using Sheffield cage traps (Sheffield Wire Products, Welshpool, Western Australia) set along multiple transects $(\leq 280$ traps/night, $100 \mathrm{~m}$ spacing) at dusk, baited with universal bait (rolled oats, peanut butter and sardines), and cleared within three hours of sunrise the following day. Monitoring was carried out over three-four consecutive nights at one (July), three (September), six (December), ten (April 2015) and eleven (May 2015) months after translocation. All post-translocation trapping except May 2015 (grid trapping; $7 \times 7$ traps, $50 \mathrm{~m}$ apart) consisted of transect trapping ( $\leq 106$ traps/night, $100-200 \mathrm{~m}$ spacing). Resident woylies within each destination site were also sampled prior to translocation (April and May 2014), using a grid (as above) and transect trapping ( $\leq 100$ traps/night, 100-200 m spacing).

The second translocation (June 2015) involved the relocation of 69 woylies ( 47 male, 22 female) from various wild sites within the Upper Warren, into an unfenced site within Dryandra woodland $\left(32.8027^{\circ} \mathrm{S}, 116.8854^{\circ} \mathrm{E}\right)$. Dryandra is situated in the Western Australian wheatbelt, roughly $250 \mathrm{~km}$ north-east of the Upper Warren (Fig. 1). The open-canopy woodlands in this region are dominated by wandoo, powderbark wandoo (Eucalyptus accedens), brown mallet (Eucalyptus astringens) and to a lesser extent marri [31]. During the translocation, woylies were captured (as above) over four consecutive nights. Monitoring was carried out over four consecutive nights at one (July), two (August), three (September), six (December), nine (March 2016) and twelve (June 2016) months following translocation. All post-release trapping except June 2016 (grid trapping, as above) consisted of transect trapping (100 traps/night, $200 \mathrm{~m} \mathrm{spacing).}$

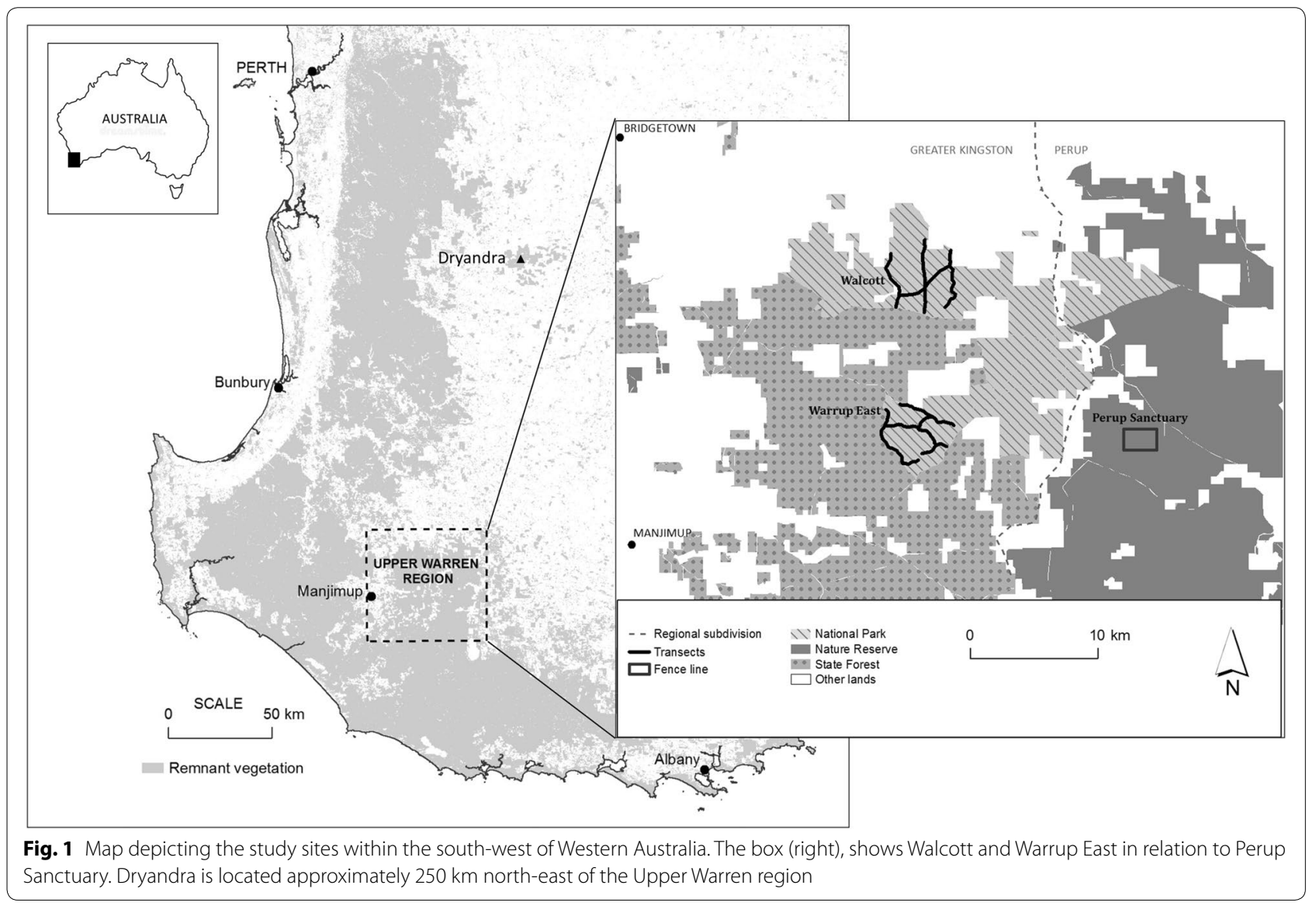


Resident woylies within the release site were also sampled prior to translocation (June 2015) using a grid and transects (as above).

\section{Woylie identification and ivermectin treatment}

Each woylie was identified with two uniquely numbered ear-tags. Prior to translocation, half of the woylies [Dryandra $(n=35)$; Walcott $(n=47)$; and Warrup East $(n=46)]$ were administered a single subcutaneous dose of ivermectin (Ivomec ${ }^{\circledR} 0.2 \mathrm{mg} / \mathrm{kg}$ ). While the ratio of treated male to female woylies was equal within the Upper Warren, there were a greater number of treated males $(24 / 35)$ than females $(11 / 35)$ within Dryandra.

\section{Haemoparasite detection}

Blood was collected from the lateral tail vein into MiniCollect $^{\circledR}$ EDTA tubes (Greiner Bio-One, Frickenhausen, Germany) and frozen at $-20{ }^{\circ} \mathrm{C}$ prior to processing. DNA was extracted from $200 \mu \mathrm{l}$ aliquots of whole blood using the QIAmp 96 DNA blood kit as per the manufacturer's instructions (Qiagen, Hilden, Germany), with a final elution volume of $60 \mu \mathrm{l}$. A negative control was included in the extraction process.

DNA was screened for the presence of trypanosomes using a nested set of generic trypanosome primers (Additional file 1: Table S1) designed by [32] and [33], which target the second fragment of the conserved $18 S$ rDNA gene region. Samples that tested positive for trypanosomes were subsequently screened for the presence of $T$. copemani, T. vegrandis and T. noyesi using specific nested primers designed by [18] and [33] (Additional file 1: Table S1). Although T. gilletti is described as a distinct species [33], it is very closely related to T. vegrandis [22], and species-specific PCR primers for T. vegrandis are unable to discriminate between the two species; thus $T$. gilletti could only be identified by DNA sequencing (see below). All PCR reactions were performed as described by [22], with the exception that $2 \mu \mathrm{l}$ of DNA was added to a $24 \mu \mathrm{l}$ master mix.

A nested PCR was used to screen for the presence of piroplasms using primers (Additional file 1: Table S1) and conditions (Additional file 1: Table S2) modified from [34]. Negative and positive controls were included in all PCR reactions, with the positive control derived from a known positive stock. Haemoparasites were identified based on expected band size for each species (Additional file 1: Table S1). PCR products were purified using either the Agencourt AMPure PCR purification system, or by using an in-house filter tip method described by [35].

Samples that tested positive for trypanosomes using the generic primer set, but negative for specific Trypanosoma species using clade-specific primers underwent Sanger sequencing at the $18 S$ rDNA locus (Additional file 1: Table S2). All piroplasm-positive samples were sequenced. Phylogenetic analyses (Additional file 1: Table S2) were conducted for putative new haemoparasites (see "Results"; Additional file 2: Figure S1, Additional file 3: Figure S2, Additional file 4: Figure S3).

\section{Data analysis}

For each haemoparasite species, prevalence of infection was calculated as the proportion of infected individuals with Jeffrey's 95\% confidence intervals (CI) calculated assuming a binomial distribution. We estimated trypanosome infracommunity richness (polyparasitism) in terms of the number of Trypanosoma spp. (T. copemani, T. vegrandis, $T$. noyesi, Trypanosoma sp. ANU2 and T. gilletti) infecting a host. Piroplasms were excluded from our analyses of parasite infracommunity richness and community composition (see below) as piroplasm infection was only assessed in a subset of translocated woylies $(n=264)$ between June and September. To evaluate the impact of site (Dryandra, Walcott and Warrup East), time since translocation (TST) and ivermectin treatment (translocated woylies only), and their interactions, on the presence of each haemoparasite species, and on Trypanosoma spp. richness, we used generalised linear mixed-effects models (package lme4, [36]) in R (version 6.1 .15 ; [37]). We could not run these models for T. noyesi, Trypanosoma sp. ANU2, T. gilletti, Th. apogeana genotype ANO2 or Babesia sp., as too few individuals were infected (prevalence $7.5 \%, 2.3 \%, 0.6 \%, 16.3 \%$ and $4.5 \%$, respectively). All analyses were conducted separately for translocated and resident woylies. For each of our models, we tested for collinearity using variance inflation factors, and residuals were checked for normality/outliers to ensure model validity. Presence/absence data for all haemoparasites were modelled as binomial variables with a logit link function. Measures of Trypanosoma spp. richness were modelled as Poisson variables with a log link function. To account for repeated measures of individuals after translocation, woylie ID was included as a random effect.

Differences in Trypanosoma spp. community composition (presence/absence data only) between translocated and resident woylies were evaluated twice for each site; pre-translocation and 6 months after translocation. For each site at each time point, dissimilarities in community composition among hosts were estimated from presence/ absence data with the Bray-Curtis coefficient. Differences in community composition between groups were visualised with non-metric multidimensional scaling plots, with the variance in mean rank order of similarity values within and between groups (R) tested for significance by a permutation technique applied to the pairwise dissimilarity matrix (one-way ANOSIM, implemented 
in PRIMER v. 6.0; [38]). The contribution of individual Trypanosoma spp. to differences in composition among host groups was assessed by averaging the Bray-Curtis coefficients for each species over all pairwise host combinations, using the SIMPER procedure in PRIMER.

\section{Results}

We analysed 1211 blood samples collected from 631 individual woylies (380 residents, 251 translocated) for the presence of haemoparasites (Additional file 1: Tables S3-S5). Of these, 49 samples could not be identified to the species level for any of the haemoparasites, so they were excluded from our analyses and prevalence estimates. Pre-translocation woylie capture rates (total number of captures divided by the total trap effort; [39]) were much higher within Walcott (0.11) compared to Warrup East (0.05) or Dryandra (0.04). DNA sequencing revealed the presence of three novel haemoparasites, which are referred to here as Trypanosoma sp. ANU2 (MF459652; a putative new species genetically characterised by [22]), Theileria apogeana genotype ANO2 (MK182522), and Bodo sp. ANO4 (MK182523). For each novel haemoparasite, genetic similarity was compared to other previously described species (Additional file 1: Table S6). Trypanosoma gilletti was also identified in woylies for the first time [22].

Overall, trypanosomes were detected in 55.3\% of samples. Of the 1162 samples that could be identified to species (or putative species), T. vegrandis was the most common (32.5\%), followed by T. copemani (23.9\%), T. noyesi $(7.5 \%)$, Trypanosoma sp. ANU2 (2.3\%) and $T$. gilletti (0.6\%). Trypanosoma sp. ANU2 and T. gilletti were only found in woylies originating from, or trapped within, the Upper Warren region (Additional file 1: Tables S3-S5). Piroplasms were highly prevalent (93.6\%) in the subset of samples we tested (translocated woylies only). Theileria penicillata was identified in $73.5 \%$ of samples, while Th. apogeana genotype ANO2 (16.3\%) and Babesia sp. (4.5\%) were comparatively rare. Theileria apogeana genotype ANO2 was common in translocated woylies originating from Perup Sanctuary, but rare outside of the reserve (Additional file 1: Tables S3-S5). Babesia sp. was infrequently detected in woylies originating from Perup Sanctuary $(n=1$, Walcott) and was predominantly isolated in woylies obtained from wild Upper Warren sites (Additional file 1: Table S3). A Bodo species (Bodo sp. ANO4) was detected in a single woylie from Perup Sanctuary.

\section{Effect of site on haemoparasite prevalence}

In translocated and resident woylies, both $T$. copemani and $T$. vegrandis prevalence differed significantly between sites (Table 1). In translocated woylies, $T$. copemani prevalence was markedly higher in Dryandra than in Walcott or Warrup East, whereas T. vegrandis prevalence was much lower in Warrup East than the other sites (Fig. 2a). In resident woylies, both T. copemani and T. vegrandis prevalence were on average highest within Walcott (particularly T. vegrandis) and lowest within Dryandra (Fig. 2b). There were no differences in Th. penicillata prevalence in translocated hosts among sites (Table 1).

Table 1 Results from generalised linear mixed model analysis of factors influencing haemoparasite prevalence and Trypanosoma spp. polyparasitism in translocated and resident woylies

\begin{tabular}{|c|c|c|c|c|c|c|c|c|c|c|c|c|}
\hline & \multicolumn{3}{|c|}{ Trypanosoma copemani } & \multicolumn{3}{|c|}{ Trypanosoma vegrandis } & \multicolumn{3}{|c|}{$\begin{array}{l}\text { Trypanosoma spp. } \\
\text { polyparasitism }\end{array}$} & \multicolumn{3}{|c|}{ Theileria penicillata } \\
\hline & $x^{2}$ & $d f$ & P & $x^{2}$ & $d f$ & P & $x^{2}$ & $d f$ & $P$ & $x^{2}$ & $d f$ & P \\
\hline \multicolumn{13}{|l|}{ Translocated } \\
\hline Site & 16.621 & 2 & $<0.001$ & 14.842 & 2 & 0.001 & 10.420 & 2 & 0.005 & 2.923 & 2 & 0.232 \\
\hline TST (time since translocation) & 4.934 & 1 & 0.026 & 28.180 & 1 & $<0.001$ & 17.054 & 1 & $<0.001$ & 2.462 & 1 & 0.117 \\
\hline Ivermectin & 0.186 & 1 & 0.666 & 0.632 & 1 & 0.426 & 0.063 & 1 & 0.802 & 1.595 & 1 & 0.207 \\
\hline Site:TST & 2.685 & 2 & 0.261 & 16.827 & 2 & $<0.001$ & 3.952 & 2 & 0.139 & 9.611 & 2 & 0.008 \\
\hline Site:Ivermectin & 3.557 & 2 & 0.169 & 5.340 & 2 & 0.069 & 8.950 & 2 & 0.011 & 1.225 & 2 & 0.542 \\
\hline TST:Ivermectin & 0.005 & 1 & 0.946 & 3.944 & 1 & 0.047 & 1.150 & 1 & 0.284 & 0.006 & 1 & 0.938 \\
\hline Site:TST:Ivermectin & 0.657 & 2 & 0.720 & 1.924 & 2 & 0.382 & 0.067 & 2 & 0.967 & - & - & - \\
\hline \multicolumn{13}{|l|}{ Resident } \\
\hline Site & 29.158 & 2 & $<0.001$ & 43.527 & 2 & $<0.001$ & 65.988 & 2 & $<0.001$ & - & - & - \\
\hline TST & 6.487 & 1 & 0.011 & 0.933 & 1 & 0.334 & 0.006 & 1 & 0.940 & - & - & - \\
\hline Site:TST & 2.744 & 2 & 0.254 & 2.757 & 2 & 0.252 & 1.740 & 2 & 0.419 & - & - & - \\
\hline
\end{tabular}

Significant $(P<0.05)$ results are highlighted in bold 


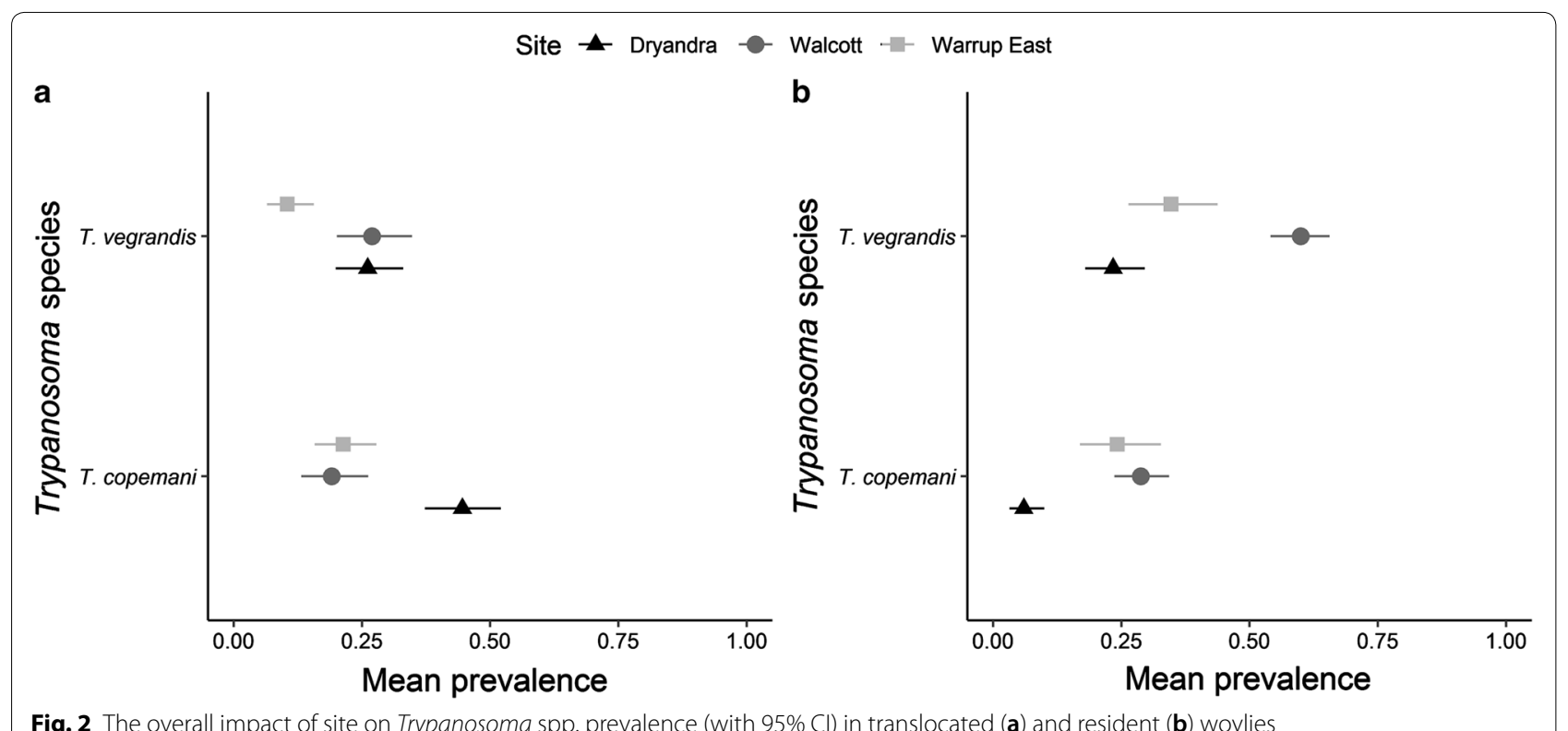

Fig. 2 The overall impact of site on Trypanosoma spp. prevalence (with $95 \% \mathrm{Cl}$ ) in translocated (a) and resident (b) woylies

\section{Effect of time since translocation on haemoparasite prevalence}

In translocated woylies, T. copemani prevalence increased in all sites with TST, while T. vegrandis prevalence increased in all sites except Warrup East, leading to a significant interaction between TST and site for this species (Table 1, Fig. 3a, b). In resident woylies, the prevalence of $T$. copemani, but not $T$. vegrandis, decreased with TST (Table 1, Fig. 3c, d).

In translocated woylies, there was a significant interaction between TST and site for Th. penicillata (Table 1), with prevalence increasing over time in Walcott and Warrup East, while remaining high within Dryandra (Fig. 4).

\section{Haemoparasite community structure in translocated and resident woylies}

In translocated and resident woylies, Trypanosoma spp. richness differed significantly between sites (Table 1, Fig. 5); being highest (on average) within Walcott. In translocated woylies, Trypanosoma spp. richness was higher in Dryandra compared to Warrup East, while in resident woylies, Warrup East had a higher species richness than Dryandra. In Trypanosoma-positive woylies, Trypanosoma spp. polyparasitism was identified in $24 \%$ of cases. The maximum number of haemoparasites (including piroplasms) identified in a single host was four (Walcott translocated group; Table 2). In translocated woylies, Trypanosoma spp. richness increased with TST (Table 1, Fig. 5a) and the prevalence of haemoparasite co-infection increased from $40 \%$ to $63 \%$ following translocation. There was no effect of TST on Trypanosoma spp. richness in resident woylies (Table 1).

Prior to translocation, Trypanosoma spp. community composition differed significantly between translocated and resident woylies in Walcott and Warrup East, but not Dryandra; this dissimilarity (84\%) was mainly associated with differences in $T$. vegrandis prevalence (Additional file 1: Tables S3-S5). Six months after translocation, there was a significant difference between translocated and resident woylies within Dryandra, but not the Upper Warren sites (Fig. 6). This dissimilarity (61\%) was largely attributed to the prevalence of $T$. copemani, which was significantly higher in translocated compared to resident woylies at all time points within Dryandra (Fig. 7).

\section{Effect of ivermectin treatment on haemoparasite prevalence and community composition}

We did not detect a significant effect of ivermectin treatment on the prevalence of any haemoparasite species in translocated woylies, although there was a marginally significant interaction $(P=0.047)$ between ivermectin treatment and TST for T. vegrandis (Table 1 ), with $T$. vegrandis prevalence being lower in treated compared to untreated hosts from September onwards (Additional file 5: Figure S4). A significant interaction between ivermectin treatment and site was also found for Trypanosoma spp. polyparasitism (Table 1). Trypanosoma species richness was lower in treated compared to untreated woylies at all time points within Dryandra, whereas species richness 


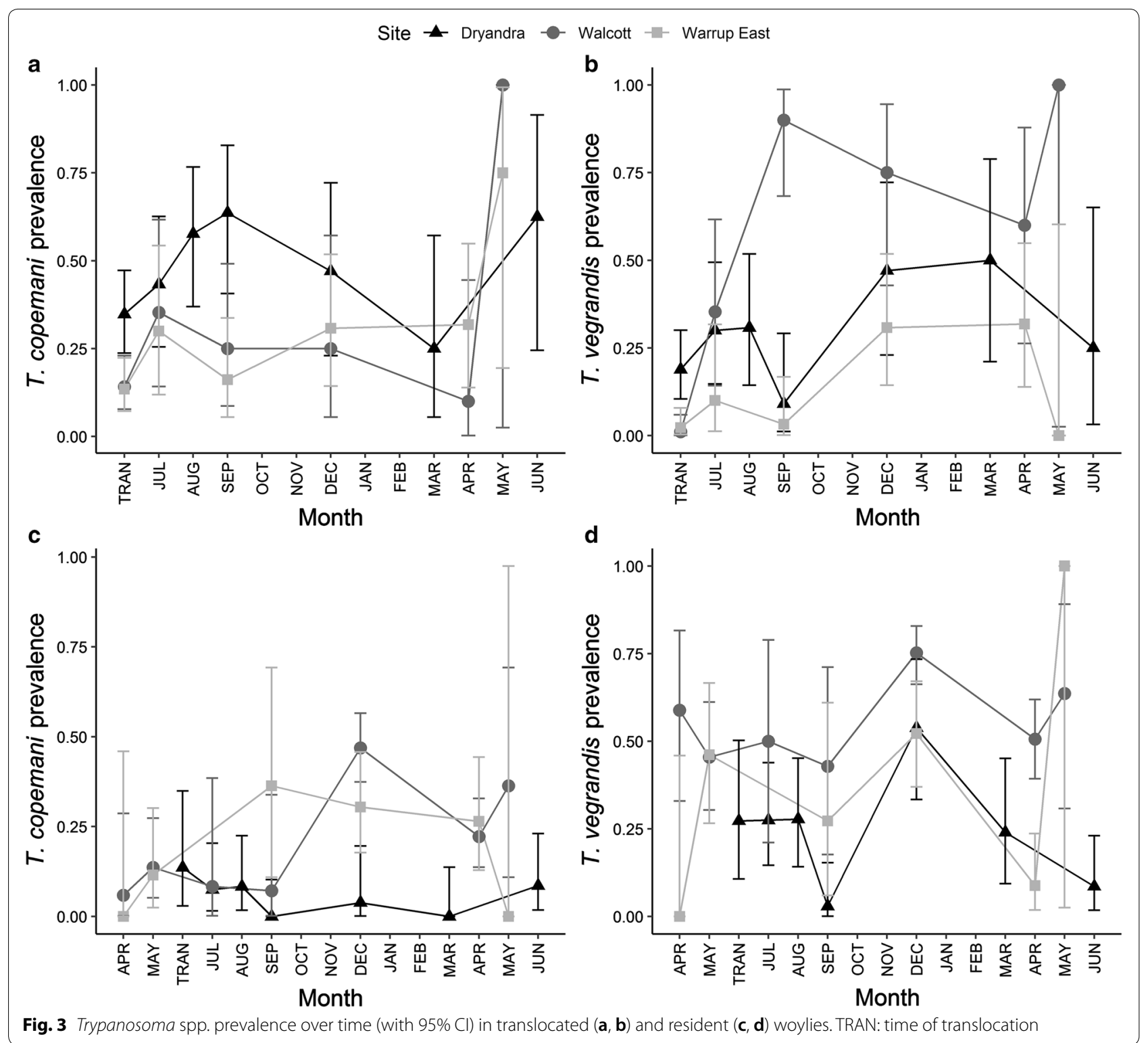

was on average higher in treated woylies within Warrup East (Additional file 6: Figure S5).

\section{Discussion}

During this study, the response of haemoparasites following translocation was highly site-specific, with major changes in haemoparasite prevalence occurring within the first few months after translocation. Trypanosoma spp. richness and the prevalence of haemoparasite coinfection increased following translocation. Trypanosoma spp. community composition became more similar over time within Walcott and Warrup East, but not Dryandra, where translocated woylies maintained a significantly higher prevalence of $T$. copemani infection compared to resident woylies. Ivermectin treatment had no significant effect on haemoparasite prevalence. We identified several new haemoparasites infecting woylies from the Upper Warren and Dryandra region. To our knowledge, this is the first published report of a Bodo sp. isolated from a marsupial blood sample; however Bodo sp. have been found previously in mammalian blood and tissue (Botero et al., unpublished data).

\section{Haemoparasite differences among sites}

An important observation from this study is that haemoparasite prevalence, Trypanosoma spp. richness and Trypanosoma spp. community composition differed significantly between sites. Overall, Walcott was the 


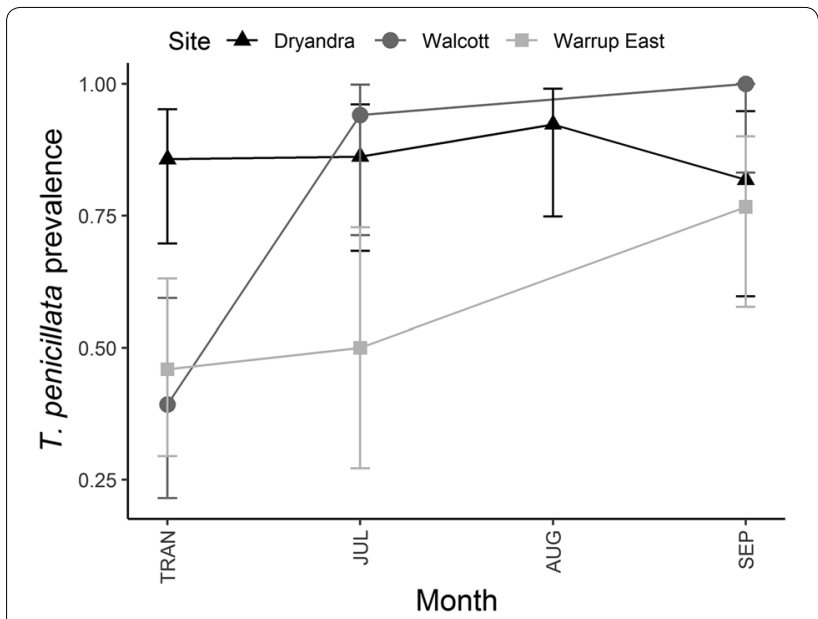

Fig. 4 Theileria penicillata prevalence over time (with 95\% Cl) in translocated woylies. TRAN: time of translocation

most parasite-rich site, whilst Dryandra was comparatively parasite-poor; though translocated hosts within Dryandra maintained a high prevalence of haemoparasite infection (particularly T. copemani) following translocation. Differences in environmental conditions, woylie population density, contact with cohabiting species and the presence/absence of appropriate vectors may all have contributed towards the differences in haemoparasite prevalence and community composition and the site specific response of haemoparasites to translocation. As the translocations to the Upper Warren and Dryandra occurred 12 months apart, we may also be observing temporal fluctuations in parasite prevalence.

We also identified apparent site specificity of certain haemoparasites during this study. The absence of Trypanosoma sp. ANU2 in Dryandra resident woylies (and translocated hosts within Dryandra post-release) suggests that this trypanosome is specific to the Upper Warren region only. The absence of Trypanosoma sp. ANU2 in cohabiting marsupials (the brushtail possum Trichosurus vulpecula hypoleucus and the chuditch Dasyurus geoffroii) within Dryandra, but not the Upper Warren (Northover et al., unpublished data) supports this theory. Site differences in the prevalence of T. gilletti, Th. apogeana genotype ANO2 and Babesia were also observed, but difficult to interpret given the low prevalence of these parasites. Site differences in the type and prevalence of parasites (and their vectors) highlights the importance of parasite monitoring, particularly with regard to the inclusion of cohabiting host species within the release site, to gain a greater understanding of the parasites a translocated host might acquire (or potentially lose) following translocation. Likewise, incorporation of a control site that monitors host-parasite dynamics in the absence of translocation would be useful for identifying normal fluctuations in parasite prevalence, however may not be realistic when working with threatened host species.

\section{Changes in haemoparasite structure over time}

In translocated woylies, significant changes in parasite prevalence occurred within the first few months after translocation, with Trypanosoma spp. richness and the
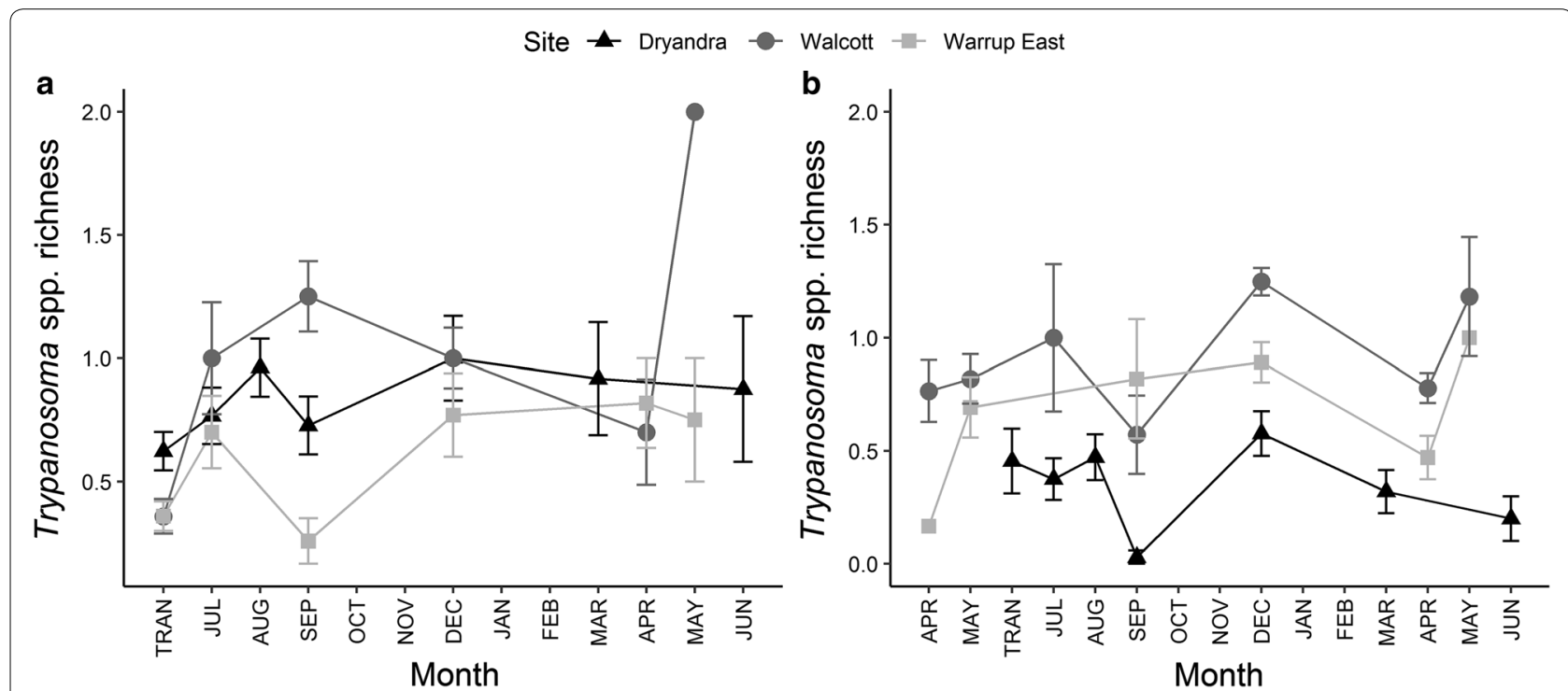

Fig. 5 Trypanosoma spp. infracommunity richness (polyparasitism) over time (with standard error bars) in translocated (a) and resident (b) woylies. Error bars represent one standard error. TRAN: time of translocation 
Table 2 The type and overall number of cases of haemoparasite co-infection identified in translocated and resident woylies from each site

\begin{tabular}{|c|c|c|c|c|}
\hline & Dryandra & Walcott & Warrup East & Total \\
\hline \multicolumn{5}{|l|}{ Translocated woylies } \\
\hline T. copemani/T. vegrandis/T. noyesi & 0 & 2 & 0 & 2 \\
\hline T. copemani/T. vegrandis & 22 & 11 & 8 & 41 \\
\hline T. copemani/T. noyesi & 0 & 5 & 3 & 8 \\
\hline T. copemani/T. ANU2 & 0 & 3 & 3 & 6 \\
\hline T. vegrandis / T. gilletti & 0 & 0 & 5 & 5 \\
\hline T. vegrandis/T. noyesi & 1 & 2 & 0 & 3 \\
\hline T. noyesi/T. ANU2 & 0 & 0 & 1 & 1 \\
\hline Th. penicillata/T. copemani/T. vegrandis $/ T$. noyesi & 0 & 1 & 0 & 1 \\
\hline Th. ANO2/T. copemani/T. vegrandis $/$. noyesi & 0 & 1 & 0 & 1 \\
\hline Th. penicillata/T. copemani/T. vegrandis & 9 & 8 & 0 & 17 \\
\hline Th. penicillata/T. copemani/T. noyesi & 0 & 3 & 2 & 5 \\
\hline Th. penicillata/T. vegrandis/T. noyesi & 0 & 2 & 0 & 2 \\
\hline Th. ANO2/T. copemani/T. ANU2 & 0 & 1 & 1 & 2 \\
\hline Th. penicillata/T. copemani & 41 & 3 & 8 & 52 \\
\hline Th. penicillata/T. vegrandis & 13 & 13 & 0 & 26 \\
\hline Th. penicillata/T. noyesi & 4 & 3 & 7 & 14 \\
\hline Th. penicillata/T. ANU2 & 1 & 1 & 1 & 3 \\
\hline Babesia/T. copemani/T. vegrandis & 1 & 0 & 0 & 1 \\
\hline Babesia/T. copemani & 5 & 0 & 0 & 5 \\
\hline Babesia/T. noyesi & 1 & 0 & 0 & 1 \\
\hline Th. ANO2/T. copemani & 1 & 1 & 2 & 4 \\
\hline Th. ANO2/T. vegrandis & 0 & 0 & 1 & 1 \\
\hline Th. ANO2/T. noyesi & 0 & 1 & 3 & 4 \\
\hline Th. ANO2/T. ANU2 & 0 & 0 & 1 & 1 \\
\hline Total & 99 & 61 & 46 & 189 \\
\hline \multicolumn{5}{|l|}{ Resident woylies } \\
\hline T. copemani/T. vegrandis/T. noyesi & 0 & 3 & 0 & 3 \\
\hline T. vegrandis/T. noyesi/T. ANU2 & 0 & 1 & 0 & 1 \\
\hline T. copemani/T. vegrandis & 9 & 50 & 6 & 65 \\
\hline T. copemani/T. noyesi & 0 & 1 & 2 & 3 \\
\hline T. copemani/T. ANU2 & 0 & 1 & 0 & 1 \\
\hline T. vegrandis/T. gilletti & 0 & 1 & 1 & 2 \\
\hline T. vegrandis/T. noyesi & 0 & 5 & 2 & 7 \\
\hline T. vegrandis/T. ANU2 & 0 & 0 & 1 & 1 \\
\hline Total & 9 & 62 & 12 & 83 \\
\hline
\end{tabular}

prevalence of haemoparasite co-infection increasing. As follow-up monitoring of reintroduced populations commonly report parasite loss during translocation [10, $29,30,40]$, this outcome was unexpected; though supplementing pre-existing populations might increase the likelihood of parasite persistence particularly when resident conspecifics are infected with the same parasites. For haemoparasites infecting a host, it would seem inevitable that they will be translocated along with their host given their location in the blood stream; however, their persistence following translocation is usually dependent upon the presence of an appropriate arthropod vector and sufficient host density to enable parasite transmission. In the case of Walcott and Warrup East, it would appear that resident woylie density and the prevalence of infection (and vectors) within each site were sufficient to maintain, and even enhance, parasitaemia in translocated woylies after translocation; which resulted in Trypanosoma spp. community composition in translocated and resident woylie groups becoming more similar 


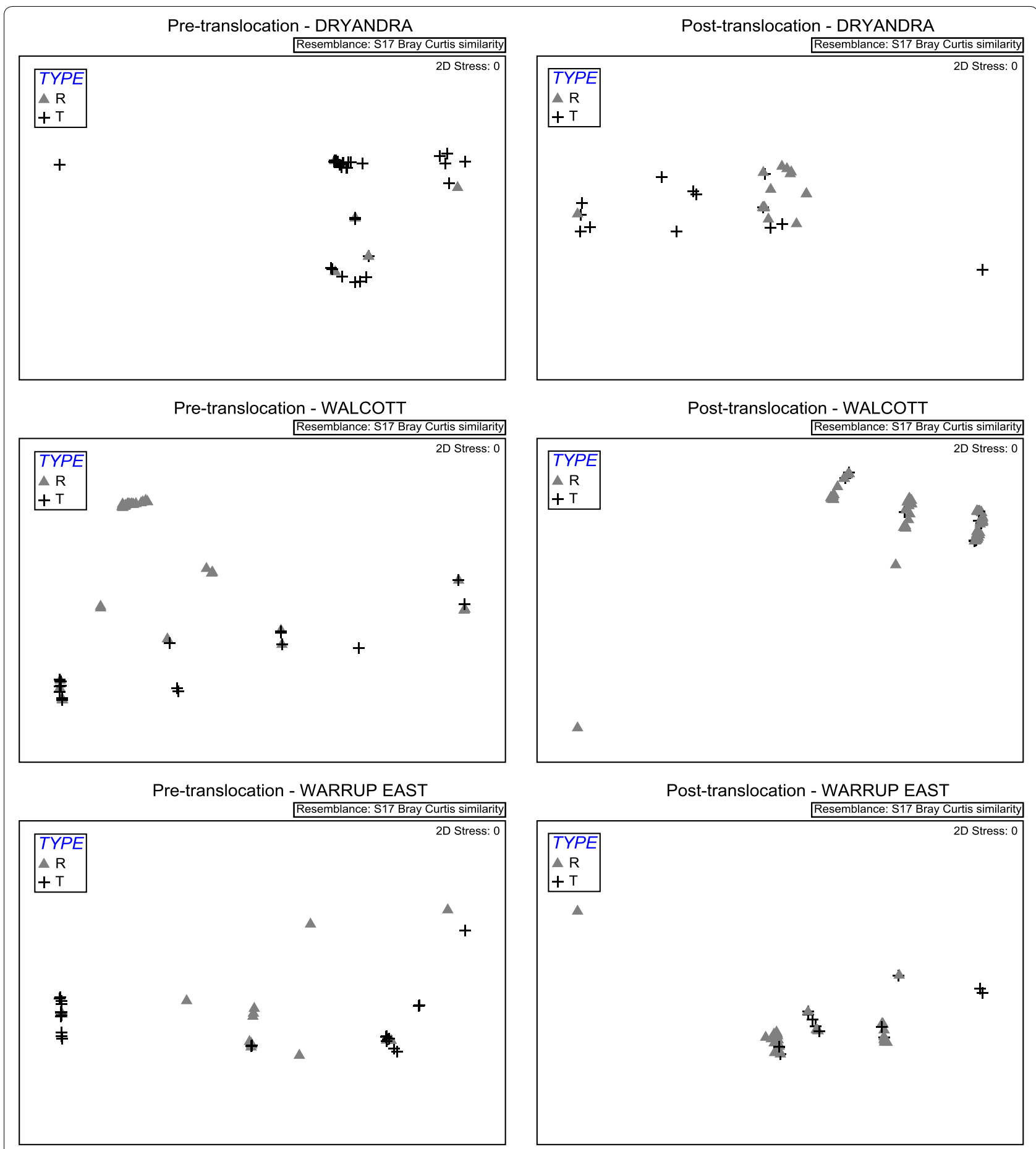

Fig. 6 Non-metric multidimensional scaling plots of parasite communities in translocated (TYPE T) and resident (TYPE R) woylies pre-translocation (left; all time points prior to and including the point of translocation) and 6 months post-translocation (right)

over time. Alternatively, enhanced parasitaemia may be the result of recrudescence of latent infections (e.g. secondary to stress), as has been reported for piroplasms in other species [41]. With the exception of T. copemani G2 (see below), however, there is no evidence to suggest that recrudescence of latent trypanosome infection occurs in woylies.

Within Dryandra, Trypanosoma spp. community composition diverged after translocation as translocated woylies maintained a significantly higher prevalence of 


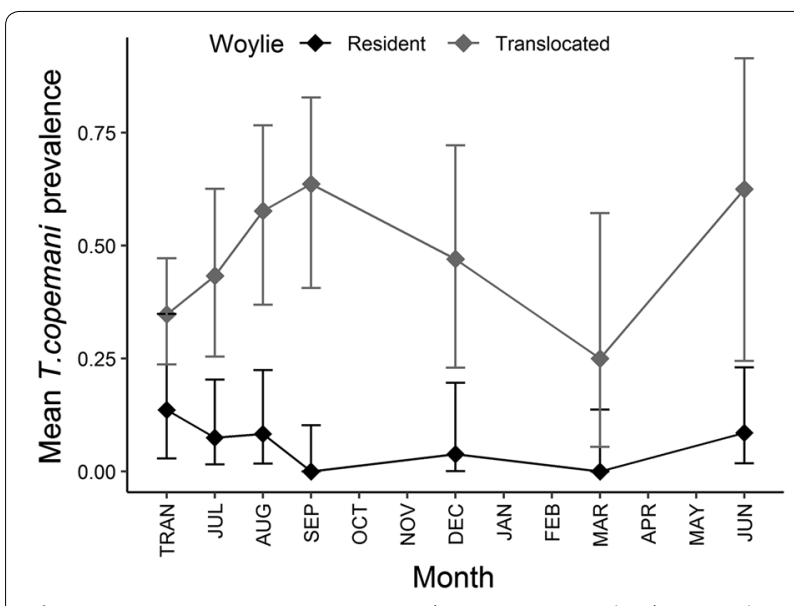

Fig. 7 Trypanosoma copemani prevalence over time (with 95\% CI) in translocated versus resident woylies within Dryandra. TRAN: time of translocation

T. copemani infection compared to residents. The introduction of translocated woylies with a much higher prevalence of $T$. copemani did not appear to affect infection prevalence in residents, which suggests that the prevalence of trypanosome vectors within Dryandra is low and/or contact with trypanosome-infected vectors/conspecifics occurs infrequently. Differences in $T$. copemani prevalence may be associated with the specific genotype of T. copemani infecting translocated and resident woylies. A high number of woylies infected with $T$. copemani G2 have been identified from the Upper Warren region [22], the origin of the translocated animals. Measurable parasitaemia associated with active Trypanosoma infection is typically transitory [42], but it has been proposed that T. copemani G2 is capable of invading tissues, replicating and sporadically re-entering the blood stream $[18,23,43]$ in a similar manner to Trypanosoma cruzi. If this is the case and if T. copemani G2 was present in translocated woylies, this could explain the consistently high detection in these animals. Alternatively, translocation-associated stress may have promoted reactivation of infection, thereby increasing the number of trypomastigotes entering the blood (and the likelihood of detecting infection in the present study). Reactivation of chronic T. cruzi infection has been linked with immunosuppression in humans [44]. While a similarity to T. cruzi is a plausible explanation, a recent study looking into the proposed intracellular life-cycle of $T$. copemani showed no evidence that $T$. copemani $\mathrm{G} 2$ can actually replicate in cells [45]. However, there is clearly an interaction between T. copemani G2 and the host that is not entirely understood. Trypanosoma copemani infection seems to be more persistent than other Trypanosoma infections [18-20] and ultimately leads to a decrease in cell health in vitro [45]. In animals that are stressed this interaction could make parasite infection more difficult to eliminate.

\section{The efficacy of ivermectin treatment}

The significant interaction between ivermectin treatment and site for Trypanosoma spp. polyparasitism was surprising. However, contrasting effects in different sites limits our ability to interpret the biological significance of this result. Likewise, the importance of the interaction between ivermectin treatment and TST for $T$. vegrandis is unclear, given the small effect we observed. If treatment-induced changes in Trypanosoma spp. polyparasitism and $T$. vegrandis prevalence are biologically significant however, this could have important consequences for host health given the association between $T$. copemani, Trypanosoma spp. co-infection, and declining woylie populations [17-20]; particularly if T. vegrandis imposes some form of competitive dominance over $T$. copemani, as previous studies have suggested [19, 46]. Further manipulative experiments that evaluate the effect of ivermectin on trypanosomes, and arthropod vectors, may be warranted if ivermectin is to be used in future woylie translocations. Likewise, studies that examine changes in the haemoparasite community in conjunction with measures of host health would assist with determining the biological significance of haemoparasite infection in woylies.

\section{Novel haemoparasite species}

Lastly, we identified three novel haemoparasites infecting woylies. Trypanosoma sp. ANU2 was first isolated from woylies during this study, and has been phylogenetically characterised by Cooper et al. [22]. The Babesia sp. we identified (Babesia sp. 28, JQ682873) has been formerly described in woylies [25], but was reported to be most similar (98.4\%; using a 527 bp alignment) to Babesia occultans, the causative agent of cattle babesiosis [47]. Our results (using a larger $693 \mathrm{bp}$ alignment) suggest that this Babesia sp. is most similar to other marsupialderived species. This is the first report of Th. apogeana genotype ANO2 in woylies, and this piroplasm is most similar to the recently described Th. apogeana from Ixodes tasmani on a dog in Tasmania [48]. Previous phylogenetic analysis [48] clustered Th. apogeana within a clade of Theileria spp. found in Australian marsupials, which was also the case here. While the vector of Th. apogeana genotype ANO2 in woylies is unknown, Ixodes australiensis and Ixodes myrmecobii were the only species of tick identified on woylies infected with Th. apogeana genotype ANO2 at the time of, or in the month preceding sample collection (Northover et al., unpublished data). 
The detection of Bodo sp. DNA in the blood of a woylie was surprising given that the group is comprised of free-living species. However, environmental contamination cannot be ruled out, in a similar way to how Bodo sp. DNA was discovered in bats [49]. Woylies are ground dwelling herbivores feeding mostly on underground fungi [14], an environment in which Bodo sp. thrive. Thus, the potential transfer of DNA through the intestinal mucosa into the host's blood circulation could be a likely consequence. However, the theory of trypanosomes evolving from free-living Bodo spp. [49] also needs to be considered.

\section{Future considerations for evaluating co-infection}

It is worth noting that our molecular screening technique may have limited our ability to accurately detect mixed infections, leading to an underestimate of the extent of polyparasitism in our study. For example, speciesspecific trypanosome primers may identify the Trypanosoma species with the greatest parasitaemia. During this study, intermittent detection of haemoparasites was common and we often observed changes in the predominant species of haemoparasite and the presence/absence of co-infection. For parasites that can only be identified via DNA sequencing (e.g. T. gilletti) it is likely that their true prevalence is under-estimated. The use of alternative screening techniques such as targeted amplicon next generation sequencing (NGS), which can be superior for detecting co-infection [22] could be used to examine polyparasitism within a host and benefit translocation planning through the identification of potentially harmful Trypanosoma genotypes (e.g. T. copemani G2) within certain populations. Given the potential role of trypanosomes in the recent decline of the woylie, which resulted in the conservation status of this species being elevated to critically endangered, NGS technology may be more adept for monitoring perturbations to the parasite community following translocation in greater detail, thus enabling more informed decisions for the management of woylies and their parasite taxa during future translocations. Despite this limitation, we still detected a relatively high (40-63\%) instance of polyparasitism in our study.

\section{Conclusions}

As fauna translocations form an integral part of fauna conservation and management, consideration needs to be given to the biological implications of altering the parasite community within a host. To our knowledge, this is the first study to evaluate haemoparasite prevalence and composition in translocated and resident animals following translocation. The results from our study suggest that major changes in the host-parasite community happen relatively quickly (within the first
3 months). The unexpected observation that Trypanosoma spp. richness and the prevalence of haemoparasite co-infection increased after translocation, suggests that the outcome of fauna supplementations may differ from reintroductions where parasite loss typically occurs. Our study adds further weight to the idea that the response of haemoparasites following translocation can be highly site-specific and further understanding of what site characteristics drive these responses would improve our ability to predict how parasites may respond to translocation. Future studies that examine haemoparasites infecting subsequent generations of woylies would be useful for identifying population level haemoparasite changes, and separating within-individual effects (e.g. prevalence fluctuating with factors such as age, stress, condition, breeding status, season) from translocation-associated effects, which we were unable to do here. Importantly, the value of long-term parasite monitoring and undertaking well-designed scientific studies that examine parasite dynamics following experimental manipulation cannot be over-emphasised, particularly with regard to the collection of comprehensive mark-recapture data that can detect changes in the parasite community over time. Lastly, consideration needs to be given to the effects of antiparasitic drug treatment, which as observed here may be indirect, with potentially adverse consequences for host health. Studies that utilise next generation sequencing rather than traditional PCR assays and Sanger sequencing will be more adept at accurately quantifying changes in the parasite infracommunity during translocation.

\section{Additional files}

Additional file 1: Table S1. Generic and species-specific primers used for the detection of haemoparasites in woylies. Table S2. Molecular methods for piroplasm PCR and Sanger sequencing/phylogenetic analyses of haemoparasites. Table S3. Number of woylies sampled within Dryandra, with prevalence of infection (and Jeffrey's 95\% CI). Table S4. Number of woylies sampled within Walcott, with prevalence of infection (and Jeffrey's 95\% Cl). Table S5. Number of woylies sampled within Warrup East, with prevalence of infection (and Jeffrey's 95\% CI). Table S6. Genetic similarity between haemoparasites isolated during this study, and other known species.

Additional file 2: Figure S1. Phylogenetic relationship of Trypanosoma sp. ANU2 MF459625 compared to other trypanosomes, inferred using maximum likelihood analysis. We have included 30 sequences from GenBank, including three outgroups (Bodo saltans, Bodo curvifilus and Trypanosoma brucei rhodesiense), to validate the 1371 bp 18 S rDNA alignment.

Additional file 3: Figure S2. Phylogenetic relationship of Theileria apogeana genotype ANO2 MK182522 (and Babesia sp. 28 JQ682873) compared to other piroplasms, inferred using the Bayesian method. Fifty nine sequences from GenBank, plus one outgroup sequence (Plasmodium falciparum M19171), have been included to validate the 693 bp 185 rDNA alignment. 
Additional file 4: Figure S3. Phylogenetic relationship of Bodo sp. ANO4 MK182523 compared to other bodonida species, inferred using the maximum likelihood analysis. Eleven sequences from GenBank, plus one outgroup sequence (AJ009142), have been included to validate the 725 bp 185 rDNA alignment.

Additional file 5: Figure S4. Trypanosoma vegrandis prevalence (all sites combined) over time (with 95\% Cl) in treated versus untreated translocated woylies (TRAN: time of translocation).

Additional file 6: Figure S5. Trypanosoma spp. polyparasitism over time (with standard error bars representing $1 \mathrm{SE}$ ) in treated versus untreated translocated woylies in (a) Dryandra and (b) Warrup East (TRAN: time of translocation).

\section{Acknowledgements}

We would like to thank Marika Maxwell, Colin Ward, Chris Vellios, Julia Wayne, Peter Wnuk, Malcolm Ovans, Brian Macmahon and other DBCA staff for their assistance in the field, and all of our dedicated volunteers, in particular James Barr, Jade Kelly, Siobhon Egan, Amy Robey and John Lawson, for their support with fieldwork, sample collection and processing. We would also like to thank Adriana Botero for providing us with technical advice regarding our molecular analyses.

\section{Funding}

This study was primarily funded by the Australian Research Council (LP130101073), but has also been assisted by grants from the Holsworth Wildlife Research Endowment (HOLSW2015-1-F149) and the Ecological Society of Australia, The Royal Zoological Society of New South Wales (Paddy Pallin Grant) and the Australian Wildlife Society.

\section{Availability of data and materials}

Sequences have been submitted to the GenBank sequence database under the accession numbers MK182522 and MK182523. The raw datasets used and/or analysed during the present study are available from the corresponding author upon reasonable request.

\section{Authors' contributions}

ASN, KM, RCAT, AJL, SSG and AFW played an instrumental role in the design and implementation of this study. ASN, SK, AJL, SSG, AFW and RCAT undertook field work and sample collection. SK, CC and LP performed all molecular laboratory work. ASN, SSG and AJL carried out data analysis. All authors read and approved the final manuscript.

\section{Ethics approval and consent to participate}

This research was undertaken in collaboration with the Department of Biodiversity, Conservation and Attractions (DBCA) under DBCA Scientific Licenses (Regulation 4: written notice of lawful authority; and 17: licence to take fauna for scientific purposes) and with approval from the Murdoch University Animal Ethics Committee (RW2659/14).

\section{Consent for publication}

Not applicable.

\section{Competing interests}

The authors declare that they have no competing interests.

\section{Publisher's Note}

Springer Nature remains neutral with regard to jurisdictional claims in published maps and institutional affiliations.

\section{Author details}

${ }^{1}$ College of Science, Health, Engineering and Education, Murdoch University, 90 South Street, Murdoch, Western Australia 6150, Australia. ${ }^{2}$ Department of Zoology, University of Otago, 362 Leith Street, Dunedin 9016, New Zealand. ${ }^{3}$ Centre for Sustainable Aquatic Ecosystems, Harry Butler Institute, Murdoch University, 90 South Street, Murdoch, Western Australia 6150, Australia. ${ }^{4}$ Biodiversity and Conservation Science, Department of Biodiversity, Conservation and Attractions, Brain Street, Manjimup, Western Australia 6258, Australia. ${ }^{5}$ Biodiversity and Conservation Science, Department of Biodiversity,
Conservation and Attractions, Wild life Place, Woodvale, Western Australia 6946, Australia.

Received: 20 November 2018 Accepted: 1 March 2019

Published online: 21 March 2019

\section{References}

1. Strickberger MW. Evolution. 3rd ed. London: Jones and Bartlett Publishers International; 2000. p. 544

2. Corn JL, Nettles VF. Health protocol for translocation of free-ranging elk. J Wildl Dis. 2001;37:413-26.

3. Keusch GT, Migasena P. Biological implications of polyparasitism. Rev Infect Dis. 1982;4:880-2.

4. Graham AL. Ecological rules governing helminth-microparasite coinfection. Proc Natl Acad Sci USA. 2008;105:566-70.

5. Telfer S, Lambin X, Birtles R, Beldomenico P, Burthe S, Paterson S, et al. Species interactions in a parasite community drive infection risk in a wildlife population. Science. 2010;330:243-6.

6. Moir ML, Vest PA, Brennan KEC, Poulin R, Hughes L, Keith DA, et al. Considering extinction of dependent species during translocation, ex situ conservation, and assisted migration of threatened hosts. Conserv Biol. 2012:26:199-207.

7. Thompson RCA, Lymbery AJ, Smith A. Parasites, emerging disease and wildlife conservation. Int J Parasitol. 2010;40:1163-70.

8. Dickens MJ, Delehanty DJ, Romero ML. Stress and translocation: alterations in the stress physiology of translocated birds. Proc Biol Sci. 2009;276:2051-6.

9. Adkesson MJ, Gorman E, Hsiao V, Whittington JK, Langan JN. Toxoplasma gondii inclusions in peripheral blood leukocytes of a red-necked wallaby (Macropus rufogriseus). Vet Clin Pathol. 2007;36:97-100.

10. Fairfield EA, Hutchings K, Gilroy DL, Kingma SA, Burke T, Komdeur J, et al. The impact of conservation-driven translocations on blood parasite prevalence in the Seychelles warbler. Sci Rep. 2016;6:29596.

11. Northover AS, Godfrey SS, Lymbery AJ, Wayne AF, Thompson RCA. The hidden consequences of altering host-parasite relationships during fauna translocations. Biol Cons. 2018;220:140-8.

12. Pedersen $A B$, Fenton $A$. The role of antiparasite treatment experiments in assessing the impact of parasites onwildlife. Trends Parasitol. 2015;31:200-11.

13. Pedersen $\mathrm{AB}$, Antonovics J. Anthelmintic treatment alters the parasite community in a wild mouse host. Biol Lett. 2013;9:220130205.

14. Richardson K. Australia's amazing kangaroos: Their conservation, unique biology and coexistence with humans. Collingwood: CSIRO Publishing; 2012. p. 23-7.

15. Wayne AF, Maxwell MA, Ward CG, Vellios CV, Wilson IJ, Wayne JC, et al. Sudden and rapid decline of the abundant marsupial Bettongia penicillata in Australia. Oryx. 2015;49:175-85.

16. Wayne AF, Maxwell MA, Ward CG, Vellios CV, Wilson IJ, Dawson KE. Woylie conservation and research project: progress report 2010-2013. Perth: Department of Parks and Wildlife; 2013.

17. Smith A, Clark P, Averis S, Lymbery AJ, Wayne AF, Morris KD, et al. Trypanosomes in a declining species of threatened Australian marsupial, the brush-tailed bettong Bettongia penicillata (Marsupialia: Potoroidae). Parasitology. 2008;135:1329-35.

18. Botero A, Thompson CK, Peacock C, Clode PL, Nicholls PK, Wayne AF, et al. Trypanosomes genetic diversity, polyparasitism and the population decline of the critically endangered Australian marsupial, the brush tailed bettong or woylie (Bettongia penicillata). Int J Parasitol Parasites Wildl. 2013;2:77-89

19. Thompson CK, Wayne AF, Godfrey SS, Thompson RCA. Temporal and spatial dynamics of trypanosomes infecting the brush-tailed bettong (Bettongia penicillata): a cautionary note of disease-induced population decline. Parasit Vectors. 2014;7:169.

20. Godfrey SS, Keatley S, Botero A, Thompson CK, Wayne AF, Lymbery AJ, et al. Trypanosome co-infections increase in a declining marsupial population. Int J Parasitol Parasites Wildl. 2018:7:221-7.

21. Botero A, Cooper C, Thompson CK, Clode PL, Rose K, Thompson RCA. Morphological and phylogenetic description of Trypanosoma noyesi sp. 
nov.: an Australian wildlife trypanosome within the T. cruzi Clade. Protist. 2016;167:425-39.

22. Cooper C, Keatley S, Northover A, Gofton AW, Brigg F, Lymbery AJ, et al. Next generation sequencing reveals widespread trypanosome diversity and polyparasitism in marsupials from Western Australia. Int J Parasitol Parasites Wildl. 2018;7:58-67.

23. Botero A, Clode PL, Peacock CS, Thompson RCA. Towards a better understanding of the life cycle of Trypanosoma copemani. Protist. 2016:167:82-92.

24. Clark P, Spencer PBS. Description of three new species of Theileria Bettencourt, Franca \& Borges, 1907 from Macropodoidea in Western Australia. Trans R Soc S Aust. 2007;131:100-6.

25. Paparini A, Ryan UM, Warren K, Mclnnes LM, de Tores P, Irwin PJ. Identification of novel Babesia and Theileria genotypes in the endangered marsupials, the woylie (Bettongia penicillata ogilbyi) and boodie (Bettongia lesueur). Exp Parasitol. 2012;131:25-30.

26. Irwin PJ. Canine babesiosis. Vet Clin North Am Small Anim Pract. 2010;40:1141-56

27. Clark P, Adlard RD, Spratt DM. Chapter 8: Haemoparasites of Australian mammals. In: Clark P, editor. Haematology of Australian mammals. Collingwood, VIC: CSIRO Publishing; 2004. p. 147-51.

28. Rong J, Bunce M, Wayne A, Pacioni C, Ryan U, Irwin P. A high prevalence of Theileria penicillata in woylies (Bettongia penicillata). Exp Parasitol. 2012;131:157-61.

29. Torchin ME, Lafferty KD, Dobson AP, McKenzie VJ, Kuris AM. Introduced species and their missing parasites. Nature. 2003;421:628-30.

30. MacLeod CJ, Paterson AM, Tompkins DM, Duncan RP. Parasites lost - do invaders miss the boat or drown on arrival? Ecol Lett. 2010;13:516-27.

31. McArthur WM, Churchward HM, Hick PT. Landforms and soils of the Murray River catchment area of Western Australia. CSIRO Australia Division Land Resource Management Series No. 3. Perth: Division of Land Resources Management, CSIRO; 1977. p. 1-23.

32. Maslov DA, Lukeš J, Jirku M, Simpson L. Phylogeny of trypanosomes as inferred from the small and large subunit rRNAs: implications for the evolution of parasitism in the trypanosomatid protozoa. Mol Biochem Parasitol. 1996;75:197-205.

33. McInnes LM, Gillett A, Hanger J, Reid SA, Ryan UM. The potential impact of native Australian trypanosome infections on the health of koalas (Phascolarctos cinereus). Parasitology. 2011;138:1-11.

34. Jefferies R, Ryan UM, Irwin PJ. PCR-RFLP for the detection and differentiation of the canine piroplasm species and its use with filter paper-based technologies. Vet Parasitol. 2007;144:20-7.

35. Yang R, Murphy C, Song Y, Ng-Hublin J, Estcourt A, Hijjawi N, et al. Specific and quantitative detection and identification of Cryptosporidum hominis and C. parvum in clinical and environmental samples. Exp Parasitol. 2013;135:142-7.
36. Bates $D$, Maechler M, Bolker B, Walker S. Fitting linear mixed-effects models using Ime4. J Stat Softw. 2015;67:1-48.

37. R Core Team. R: A language and environment for statistical computing. Vienna: R Foundation for Statistical Computing. http://www.R-proje ct.org/. Accessed 30 Jan 2019.

38. Clarke KR, Gorley RN. PRIMER v6: User manual/tutorial (plymouth routines in multivariate ecological research). Plymouth: PRIMER-E; 2006.

39. Wayne AF, Maxwell MA, Ward CG, Vellios CV, Ward BG, Liddelow GL, et al. Importance of getting the numbers right: quantifying the rapid and substantial decline of an abundant marsupial, Bettongia penicillata. Wildl Res. 2013;40:169-83.

40. Portas TJ, Cunningham RB, Spratt D, Devlin J, Holz P, Batson W, et al. Beyond morbidity and mortality in reintroduction programmes: changing health parameters in reintroduced eastern bettongs Bettongia gaimardi. Oryx. 2016;50:674-83.

41. Alvarado-Ryback M, Solano-Gallego L, Millan J. A review of piroplasmid infections in wild carnivores worldwide: importance for domestic animal health and wildlife conservation. Parasit Vectors. 2016;9:538.

42. Campos R, Botto-Mahan C, Ortiz S, Coronado X, Solari A. Temporal fluctuation of infection with different Trypanosoma cruzi genotypes in the wild rodent Octodon degus. Am J Trop Med Hyg. 2010;83:380-1.

43. Thompson CK, Botero A, Wayne AF, Godfrey SS, Lymbery AJ, Thompson RCA. Morphological polymorphism of Trypanosoma copemani and description of the genetically diverse $T$. vegrandis sp. nov. from the critically endangered Australian potoroid, the brush-tailed bettong (Bettongia penicillata (Gray, 1837)). Parasit Vectors. 2013;6:121.

44. Perez CJ, Lymbery AJ, Thompson RCA. Reactivation of Chagas disease: implications for global health. Trends Parasitol. 2015;31:595-603.

45. Cooper C, Thompson RCA, Rigby P, Buckley A, Peacock C, Clode PL. The marsupial trypanosome Trypanosoma copemani is not an obligate intracellular parasite, although it adversely affects cell health. Parasit Vectors. 2018;11:521.

46. Lymbery AJ, Thompson RCA. The molecular epidemiology of parasite infections: tools and applications. Mol Biochem Parasitol. 2012:181:102-16.

47. Gray JS, de Vos AJ. Studies on a bovine Babesia transmitted by Hyalomma marginatum rufipes Koch, 1844. Onderstepoort J Vet Res. 1981;48:215-23.

48. Greay TL, Zahedi A, Krige A-S, Owens JM, Rees RL, Ryan UM, et al. Endemic, exotic and novel apicomplexan parasites detected during a national study of ticks from companion animals in Australia. Parasit Vectors. 2018;11:197.

49. Szoke K, Sandor A, Boldogh S, Gorfol T, Votypka J, Takacs N, et al. DNA of free-living bodonids (Euglenozoa: Kinetoplastea) in bat ectoparasites: potential relevance to the evolution of parasitic trypanosomatids. Acta Vet Hung. 2017;65:531-40.
Ready to submit your research? Choose BMC and benefit from:

- fast, convenient online submission

- thorough peer review by experienced researchers in your field

- rapid publication on acceptance

- support for research data, including large and complex data types

- gold Open Access which fosters wider collaboration and increased citations

- maximum visibility for your research: over $100 \mathrm{M}$ website views per year

At BMC, research is always in progress.

Learn more biomedcentral.com/submissions 